Guanidine acetate, used instead of the thiocyanate, gave the same condensation-product.

An attempt was made to prepare the naphttetrazine by direct fusion of succinylosuccinic ester and guanidine acetate, in the same way that the dimine was made from succinylosuccinic ester and ammonium acetate, but no condensation occurred.

Finally, a solution of free guanidine was prepared from the carbonate and condensed with succinylosuccinic ester, but this variation showed no advantage over the use of a guanidine salt and sodium ethylate either in the yield or purity of the product.

HAVEMEYER LABORATORIES, COLUMBIA UNIVERSITY, April, 1905.

[CONTRIbution From THE JOHN HARRison LAboratory of ChemISTRY, No. 90.]

\title{
DOUBLE FLUORIDES OF TANTALUM. ${ }^{1}$
}

By Clarence W. BaLKe.

Received July I2, I905.

THE results set forth in this article constitute a chapter in the reinvestigation of the compounds of columbium and tantalum now in progress in this laboratory. While partly confirmatory in nature, they mark a distinct advance in certain directions, and, it is hoped, will materially aid in a continuation of the investigation.

Berzelius $^{2}$ first prepared and analyzed the potassium salt, $2 \mathrm{KF} . \mathrm{TaF}_{5}$. In addition he mentioned a calcium, a magnesium, and a lead salt, and further, a potassium salt containing as much as 63 per cent. of tantalic acid, and an ammonium salt, but these were not analyzed, nor were any formulas assigned to them.

$H$. Rose ${ }^{3}$ prepared and analyzed the potassium salt and also the 3: I sodium salt, $3 \mathrm{NaF} . \mathrm{TaF}_{5}$.

Marignac, ${ }^{4}$ in 1866 , published the most complete investigation of these salts which has been made up to the present time. $\mathrm{He}$ studied the ammonium, potassium, sodium, zinc and copper salts.

A. Joly $y^{5}$ described an ammonium oxyfluoride of tantalum of the

1 From author's thesis presented to the University of Pennsylvania for the Ph.D. degree.

2 Pogg. Ann, 4,6 (1825).

3 Ibid., $99,48 \mathrm{I}(1856)$.

4 Bibl. Univ. Arch., 26, 89; Ann. ch. Phys. [4], 9, 247 (1866).

5 C, R., 81, I266 (I875). 
composition $3 \mathrm{NH}_{4} \mathrm{~F} \cdot \mathrm{TaOF}_{3}$. No analyses were given, and the existence of such a salt cannot be considered as well established.

A. Piccini ${ }^{1}$ prepared and analyzed a potassium tantalum double fluoride of the composition, $2 \mathrm{KF} \cdot \mathrm{TaO} \mathrm{O}_{2} \mathrm{~F}_{3} \cdot \mathrm{H}_{2} \mathrm{O}$.

Finally, Mary Engle Pennington ${ }^{2}$ prepared the rubidium salt, and a caesium salt to which the composition, ${ }_{5} \mathrm{CsF}_{\text {.TaF }}$, was assigned. This latter salt was not encountered by the writer.

The existence of the following double fluorides may be considered as beyond question:

$$
\begin{aligned}
& { }_{2} \mathrm{NH}_{4} \mathrm{~F} \cdot \mathrm{TaF}_{5} \\
& 2 \mathrm{KF} \mathrm{TaF}_{5} \\
& { }_{2} \mathrm{KF} \cdot \mathrm{TaO}_{2} \mathrm{~F}_{3} \cdot \mathrm{H}_{2} \mathrm{O} \\
& { }_{3} \mathrm{NaF}_{\mathrm{TaF}} \mathrm{TaF}_{5} \\
& 2 \mathrm{NaF} \cdot \mathrm{TaF}_{5} \cdot \mathrm{H}_{2} \mathrm{O} \\
& { }_{2} \mathrm{RbF} \mathrm{TaF}_{5} \\
& \mathrm{ZnF}_{2} \cdot \mathrm{TaF}_{5} .7 \mathrm{H}_{2} \mathrm{O} \\
& \mathrm{CuF}_{2} \cdot \mathrm{TaF}_{5} \cdot{ }_{4} \mathrm{H}_{2} \mathrm{O}
\end{aligned}
$$

In the present study a number of them have been reinvestigated, and the following new salts have been obtained:

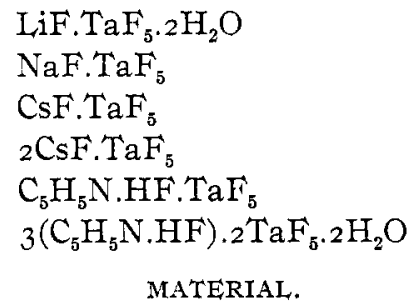

The tantalic oxide used in the preparation of these salts was obtained from the columbite of South Dakota, large amounts of which have been worked up in this laboratory by R. D. Hall. ${ }^{3}$ The potassium tantalum fluoride, obtained as a crystalline precipitate upon the addition of potassium fluoride to the hydrofluoric acid solution of the mixed metallic oxides, was purified in the following manner. About 2300 grams of the salt were recrystallized from water containing enough hydrofluoric acid to prevent the formation of an oxy-salt. At first considerable difficulty was encountered in making the solutions and filtrations, due to the comparative insolubility of the salt, and its rapid

t Z. anorg. Chem, a, $21(t 892)$.

2 This Journal, 18, $3^{8}$ (1896).

Ibid., 26, I235 (I904). 
separation in the funnel. However, with the large platinum and rubber dishes provided for the purpose, this difficulty was soon overcome.

The salt was brought into solution in a 5 liter platinum dish, ${ }^{1}$ and when the solution had become saturated at a temperature not far below its boiling-point, it was decanted through a large rubber funnel surrounded by boiling water. The solution was collected in hard rubber dishes, having a capacity of about 5 liters, and allowed to cool. The crystals which separated were removed, and the mother-liquor was returned to the large platinum dish to be again saturated with the salt. In this way the necessity of evaporating the solutions was eliminated. The potassium columbium oxyfluoride and other impurities concentrated in the mother-liquor, and after the entire amount of salt had passed through the solution in the manner just indicated, about 200 grams of salt were finally discarded in the mother-liquor. These crystallizations were repeated three times, and at the completion of each crystallization, a large amount of salt was allowed to remain in the mother-liquors. The mother-liquor from the first crystallization contained considerable potassium columbium fluoride, while that from the last crystallization was practically free from columbium.

The potassium tantalum fluoride obtained in this way was now free from impurities with the exception of silica, it being impossible to remove this impurity by crystallization alone. The salt, in 500-gram lots, was mixed with at least twice its weight of concentrated sulphuric acid and heated in a 3 -liter platinum dish over a battery of four Bunsen burners. The heating was continued until the mass had assumed the consistency of a thick paste. By this treatment any silica present must have been eliminated. The mass was next boiled up repeatedly with large amounts of water, and the white oxide obtained was repeatedly washed by decantation.

The purity of this oxide was tested as follows. The first extract obtained after the treatment of the potassium tantalum fluoride with sulphuric acid was examined for iron, with negative results. Twenty-five grams of the oxide were fused with sodium carbonate and sulphur, and the aqueous extract of the fusion was examined for tin and tungsten, again with negative results. A

I The dish consisted of a platinum lining supported by a nickel shell. 
potassium binoxalate solution of its hydrate gave no coloration with hydrogen peroxide, indicating the absence of titanium.

Tantalum oxide prepared in this manner dissolved readily in aqueous hydrofluoric acid to a clear solution, which served for the preparation of the double fluorides to be described.

All of the hydrofluoric acid used in the present investigation was carefully distilled from a platinum retort, potassium hydroxide being added to hold back any silica in the commercial acid.

\section{LITHIUM SALT.}

LiF. TaF ${ }_{5} .2 \mathrm{H}_{2} \mathrm{O}$.- Though difficultly soluble in water, lithium fluoride was found to dissolve quite readily in a strong hydrofluoric acid solution of hydrofluotantalic acid. In the preparation of the above salt 40 grams of tantalic oxide were dissolved in strong hydrofluoric acid, and to this solution Io grams of lithium carbonate were added. A clear solution resulted and this, after concentration on the water-bath and subsequent cooling, deposited colorless crystals, which were found to have the composition indicated above. They were recrystallized with ease from strong hydrofluoric acid. On standing in the air, the crystals gradually lost their luster. This was observed to be generally true with the double fluorides which contained water of crystallization, while the anhydrous salts retained their brilliancy for months.

Analysis.-The salt was weighed into a platinum crucible and covered with several times its weight of concentrated sulphuric acid. The crucible was heated gently at first, and then more strongly until the greater part of the acid had been expelled. The mass was then boiled up with water and the tantalum oxide filtered out. It was often noticed that this precipitate decrepitated upon ignition, so that care had to be exercised in order to prevent loss of material. The filtrate from the tantalum oxide was evaporated in a platinum crucible, and the latter was then ignited, the lithium being weighed as sulphate. With one of two exceptions to be noted later, this method of analysis was employed for all of the double fluorides of tantalum with the alkali metals.

To determine the water, the salt was mixed with lead oxide and carefully ignited, the water being collected in a weighed calcium chloride tube. 


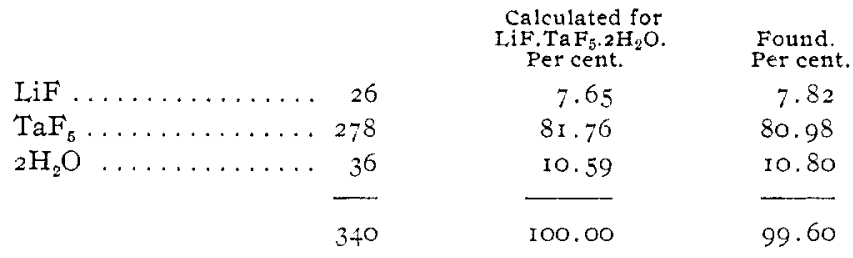

Crystallography. ${ }^{1}$-The salt crystallized in the monoclinic system. The crystal habit was quite simple, as may be observed from the accompanying figure. The clinodome (or2) was ob-

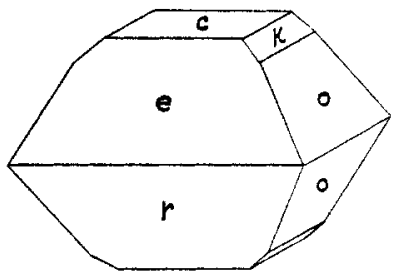

Fig. 1.

served on only a few of the crystals. The latter were several $\mathrm{mm}$. in diameter, but their faces were not sufficiently smooth to admit of the most accurate measurement. The measurements chosen as fundamental are indicated by an asterisk.

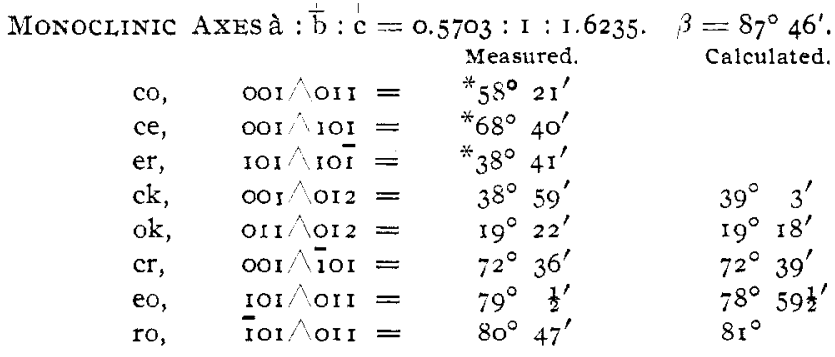

SODIUM SALTS.

Two double fluorides of sodium and tantalum have been described, $3 \mathrm{NaF}^{-\mathrm{TaF}_{5}}$ and ${ }_{2} \mathrm{NaF} \cdot \mathrm{TaF}_{5} \cdot \mathrm{H}_{2} \mathrm{O}$. Marignac prepared them by dissolving sodium tantalate, $3 \mathrm{Ta}_{2} \mathrm{O}_{5} .4 \mathrm{Na}_{2} \mathrm{O} .24 \mathrm{H}_{2} \mathrm{O}$, in hydrofluoric acid and concentrating the solution. The first crops constituted the $3: \mathrm{r}$ salt, and their removal left a mother-liquor

1 The author wishes to take this opportunity to express his thanks to Professor Amos P. Brown for many valuable suggestions in connection with the crystallographic part of this investigation. 
richer and richer in tantalum fluoride, until finally the $2:$ I salt crystallized out.

$3 \mathrm{NaF}_{\mathrm{TaF}}$.-This is the characteristic double fluoride of tantalum with sodium. It is produced when the $2: \mathrm{I}$ salt is recrystallized, the latter being formed only in the presence of an excess of tantalum fluoride. In the present instance sodium fluoride and tantalum fluoride were mixed in the proportion of 4: $\mathrm{r}$, and the solution was concentrated on the water-bath. On cooling, the above salt separated in rather indistinct forms, which, however, on recrystallization from water containing a small amount of hydrofluoric acid, separated in well formed, exceedingly brilliant, orthorhombic crystals. This salt was more stable than the $2:$ I potassium salt, being soluble in boiling water without the separation of an oxy-salt, but as hydrofluoric acid was lost in the escaping vapor, it was always recrystallized from water containing some acid. When the dry salt was heated in a platinum crucible, it decrepitated, fused to a clear liquid, and slowly decomposed on stronger heating.

Its solubility was determined as follows: A saturated solution of the salt was obtained by allowing the crystals to remain in contact with the solution in a rubber beaker for several hours, the solution being stirred from time to time. The clear liquid was decanted into a weighed platinum dish and the latter reweighed. The solution was then evaporated to dryness on the water-bath, a few drops of hydrofluoric acid being added when the evaporation had become nearly complete. The dish with the dry salt was again weighed. Two determinations were made, in which $\mathrm{I}$ gram of the salt was found to dissolve in 20.9 and in 20.5 parts of water at $25^{\circ} \mathrm{C}$.

When titrated with an alkali, the point of neutrality was reached at the completion of the reaction

$$
{ }_{3} \mathrm{NaF} \cdot \mathrm{TaF}_{5}+{ }_{5} \mathrm{NaOH}=\mathrm{Ta}(\mathrm{OH})_{5}+8 \mathrm{NaF} \text {. }
$$

0.486 I gram required $37.2 \mathrm{cc}$. of a solution of sodium carbonate, I cc. of which contained 0.0038 gram of sodium, which corresponds to 24.03 per cent. of fluorine, that calculated for $5 \mathrm{~F}$ being $23.5 \mathrm{I}$ per cent.

The analysis of this salt was conducted as in the case of the lithium salt. In the following table the results obtained by $\mathrm{H}$. Rose and Marignac are included. 


\begin{tabular}{|c|c|c|c|c|c|c|c|c|c|}
\hline \multirow[b]{2}{*}{$3 \mathrm{NaF}$} & \multicolumn{2}{|c|}{$\begin{array}{c}\text { Calculated for } \\
3 \mathrm{NaF}^{2} \mathrm{TaF}\end{array}$} & \multirow{2}{*}{$\begin{array}{l}\text { I. } \\
3 I .28\end{array}$} & \multirow{2}{*}{$\begin{array}{c}\text { II. } \\
31.32\end{array}$} & \multicolumn{2}{|c|}{ H. Rose. } & \multicolumn{3}{|c|}{ Marignac. } \\
\hline & I 26 & 31.19 & & & 30.28 & $32.6 \mathrm{r}$ & $3 I .26$ & 31.29 & \\
\hline $\mathrm{TaF}_{3}$ & 278 & $68.8 \mathrm{I}$ & 68.45 & $68.6 \mathrm{I}$ & 67.22 & 67.46 & 68.68 & 67.66 & 69.19 \\
\hline & $\begin{array}{l}404 \\
152\end{array}$ & $\begin{array}{r}100.00 \\
37.62\end{array}$ & $99 \cdot 73$ & 99.93 & 97.50 & 7 & $\begin{array}{l}99.94 \\
37.83\end{array}$ & 95 & \\
\hline
\end{tabular}

Crystallography.-The form of this salt is orthorhombic. It showed a marked monoclinic aspect, and was thought at first to belong to the monoclinic system. Careful measurements, however, proved that the a axes and $c$ axes would be of equal length if the crystals were referred to the latter system, and further, the crystals were observed to extinguish parallel to the face $a$ (see figures). Many of the crystals grew out into the solution in the form of apparent six-sided prisms due to an elongation parallel to the axis of a zone containing two prisms and four pyramid faces. Such a crystal is shown in Fig. 4, and this seems to be the characteristic habit of the salt, though some crystals were observed with terminations on both ends. Fig. 2 is a projection on the plane of the lateral axes and indicates the relative positions of the faces, while Fig. 3 is a similar projection of an actual crystal.

In many of the crystals the faces of the pyramid ( $\mathrm{I}_{3} \mathrm{I}$ ) were but slightly developed or entirely absent. The best crystals were ob-

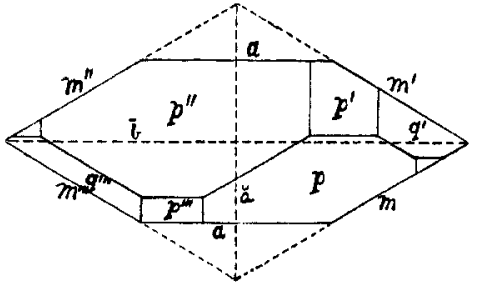

Fig, 2 .

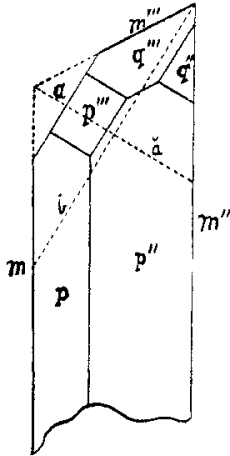

Fig. 3.

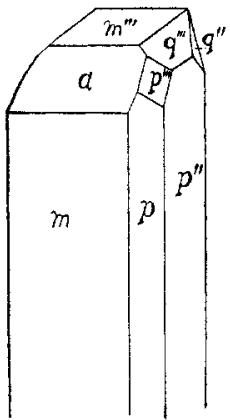

Fig. 4 .

tained by allowing a hot saturated solution of the salt, contained in a platinum dish, to cool slowly over night. This was accomplished by placing the dish in a large tank of hot water and surrounding the latter with non-conducting material. The crystals obtained in this way were several millimeters in length and very 
sharply defined. They were exceedingly brilliant and gave excellent reflections.

Orthorhombic.-Axes $\breve{a}: \bar{b}: \dot{c}=0.6017:$ I: 0.2799 .

\begin{tabular}{|c|c|c|c|}
\hline & & Measured. & Calculated. \\
\hline $\mathrm{mm}^{\prime \prime \prime}$, & IIO $\bigwedge \mathrm{IIO}=$ & ${ }^{*} 62^{\circ} \quad 4^{\prime}$ & \\
\hline $\mathrm{mp}$, & IIO $\wedge$ III $=$ & ${ }^{*} 6 \mathrm{I}^{\circ} 3 \mathrm{O}^{\prime}$ & \\
\hline $\mathrm{pp}^{\prime \prime}$, & III & ${ }^{*} 57^{\circ}$ & \\
\hline $\mathrm{pp}^{\prime}$, & $\operatorname{III} \wedge \bar{I}_{I I}=$ & $48^{\circ}$ I $2^{\prime}$ & $48^{\circ} \quad 16^{\prime}$ \\
\hline $\mathrm{pp}^{\prime \prime \prime}$ & $\operatorname{III} \wedge \bar{I} \bar{I}=$ & $28^{\circ} 33^{\prime}$ & $28^{\circ} 29^{\prime}$ \\
\hline ap, & $100 \wedge \mathrm{III}=$ & $65^{\circ} 52^{\prime}$ & $65^{\circ} 52^{\prime}$ \\
\hline $\mathrm{m}^{\prime \prime \prime} \mathrm{p}$ & $\operatorname{I} \bar{I} O \wedge I I I=$ & $77^{\circ}$ & $77^{\circ} \quad 5^{\prime}$ \\
\hline $\mathrm{mq}$, & IIO $\wedge$ I $3 I=$ & $53^{\circ} \quad 8^{\prime}$ & $53^{\circ} \quad 8 \frac{1}{2}^{\prime}$ \\
\hline$q p^{\prime}$ & I3I $\overline{I I I I}=$ & $49^{\circ} 48^{\prime}$ & $49^{\circ} 46 \frac{1}{2}^{\prime}$ \\
\hline$q p$, & I3I $\wedge$ III $=$ & $22^{\circ} 56 \frac{1}{2}^{\prime}$ & $22^{\circ} 59^{\prime}$ \\
\hline $\mathrm{qq}^{\prime}$, & $I_{3} I \wedge \bar{I}_{3} I=$ & $39^{\circ}$ I $3^{\prime}$ & $39^{\circ} \mathrm{I} 3^{\prime}$ \\
\hline
\end{tabular}

${ }_{2} \mathrm{NaF}_{\mathrm{TaF}} \cdot \mathrm{H}_{2} \mathrm{O}$. - This salt was studied by Marignac. It may be obtained in the form of thin plates when a solution containing sodium fluoride and a rather large excess of tantalum fitoride is concentrated and allowed to cool. On recrystallization, it passed into the 3 : I salt just described. Its analysis was conducted as in the case of the lithium salt.

\begin{tabular}{|c|c|c|c|c|c|c|}
\hline \multirow[b]{2}{*}{$2 \mathrm{NaF}$} & \multicolumn{2}{|c|}{$\begin{array}{l}\text { Calculated for } \\
\text { 2NaF.TaF }_{5} \mathrm{H}_{2} \mathrm{O} \text {. }\end{array}$} & \multicolumn{2}{|c|}{ Found. } & \multicolumn{2}{|c|}{ Marignac. } \\
\hline & 84 & $22 . \mathrm{II}$ & 22.15 & 22.40 & $22.5 \mathrm{I}$ & 22.17 \\
\hline $\mathrm{TaF}_{5} \ldots \ldots$ & 278 & 73.17 & 72.94 & 72.49 & 72.74 & 73.02 \\
\hline $\mathrm{H}_{2} \mathrm{O}$ & I 8 & $4 \cdot 74$ & 4.82 & 4.95 & 4.63 & $\ldots$ \\
\hline & 380 & 100.00 & 99.91 & 99.84 & 99.88 & \\
\hline
\end{tabular}

NaF. $\mathrm{TaF}_{5}$. - The mother-liquor from the $2:$ I salt contained a large amount of tantalum fluoride, with only a small amount of sodium fluoride. From this solution there separated, after it had stood undisturbed for several weeks, a salt consisting of shining cubes belonging to the isometric system. While this salt was obtained only in small amount, the results seem to be sufficient to establish the existence of this ratio. It must be remembered that the highest purity cannot be expected in the case of double salts which are only formed in the presence of a large excess of one of the constituents and which cannot be purified by recrystallization.

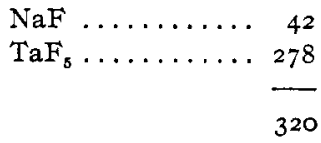

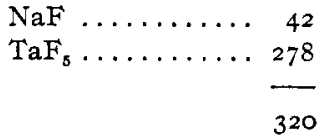

Calculated for NaF.TaF

Found,

I3. I 2

86.88

100.00
I3. 58

86.27

99.85 
POTASSITM SALTS.

$2 K F \cdot T a F_{5}$. - This is the most important double fluoride of tantalum. From it, pure tantalic acid is obtained. By means of it, tantalum is separated from columbium. It was studied by Berzelius, H. Rose and Marignac. It is formed when the two fluorides are brought together in a dilute aqueous solution of hydrofluoric acid, and consists of small, but well-defined, anhydrous needles. On preservation it slowly gives off hydrofluoric acid, indicated by the etching of glass bottles containing the dry salt. For this reason neither this nor any of the other double fluorides were preserved in glass, but rather in clean pasteboard boxes. This salt was found to be much more soluble in hot than in cold water. Its solubility in the latter is given by Marignac to be I : 200 parts of water containing a small amount of hydrofluoric acid. Its solubility in pure water could not be determined as an insoluble oxyfluoride separates from the solution. This latter compound was also formed when a solution of potassium tantalum fluoride was boiled, provided that only a very small amount of free hydrofluoric acid was present. According to the analyses made by Marignac this white precipitate approached the composition indicated by the formula, $\mathrm{Ta}_{2} \mathrm{O}_{5}+2\left(2 \mathrm{KF} \cdot \mathrm{TaF}_{5}\right)$. This body was quite insoluble in water, but dissolved readily in hydrofluoric acid, and from the solution so obtained, the normal double fluoride again separated. On heating the dry normal salt in a platinum crucible it decrepitated and then fused to a clear colorless liquid.

The following analyses are given by the above-named investigators.

\begin{tabular}{|c|c|c|c|c|c|c|}
\hline \multirow[b]{3}{*}{$2 \mathbf{K}$} & & & \multirow{2}{*}{$\begin{array}{l}\text { Calculated for } \\
2 \mathrm{KF} \text {. IaF }\end{array}$} & \multicolumn{3}{|c|}{ Found. } \\
\hline & & & & Berzelius. & H. Rose. & Marignac. \\
\hline & $\ldots$ & 78 & 19.80 & 19.54 & 20.60 & 19.85 \\
\hline Ta & $\ldots \ldots$ & 183 & $\mathrm{Ta}_{2} \mathrm{O}_{5}, 56.60$ & 56.99 & 53.18 & 56.59 \\
\hline $7 \mathrm{~F}$ & $\ldots \ldots$ & I 33 & 33.79 & & & $33 \cdot 4^{2}$ \\
\hline
\end{tabular}

Marignac employed this salt for the determination of the atomic weight of tantalum. The results of his analyses are given in the first two columns, while the third shows the atomic weight of tantalum calculated on the basis of $\mathrm{O}=16, \mathrm{~K}=39.15$ and $\mathrm{S}=32.06$. 


$\begin{array}{ccc}\begin{array}{c}\mathrm{Ta}_{2} \mathrm{O}_{5} . \\ \text { Per cent. }\end{array} & \begin{array}{c}\mathrm{K}_{2} \mathrm{SO}_{4} \\ \text { Per cent. }\end{array} & \text { At. wt. of Ta. } \\ 56.50 & 44.37 & \text { I } 82.03 \\ 56.75 & 44.35 & \text { I } 83 . \mathrm{II} \\ 56.55 & 44.22 & \text { I } 82.98 \\ 56.56 & 44.24 & \text { I } 82.92\end{array}$

${ }_{2} \mathrm{KF} \cdot \mathrm{TaO}_{2} \mathrm{~F}_{3} \cdot \mathrm{H}_{2} \mathrm{O}$. - This salt has already been prepared by $\mathrm{A}$. Piccini. During the present investigation it was obtained by dissolving potassium tantalum fluoride in a hot, dilute, aqueous solution of hydrofluoric acid, and adding an equal volume of a 3 per cent. solution of hydrogen peroxide. On cooling, pearly leaflets separated from the liquid. They closely resembled in appearance the crystals of potassium columbium oxyfluoride. They were again crystallized from water containing some hydrogen peroxide and hydrofluoric acid. They were much more soluble than the normal potassium tantalum fluoride, and ammonium hydroxide did not precipitate the tantalum from their solution. On the other hand, precipitation took place at once in solutions of the normal salt. The addition of a small amount of alcohol along with the ammonium hydroxide produced a precipitate of tantalum hydroxide. The water was driven out of the salt at a much lower temperature than the active oxygen. This fact led Piccini to write the formula of the salt as indicated above.

Analysis.-One portion of the salt was dissolved in water in a platinum dish, boiled with a little alcohol and ammonium hydroxide, and the tantalum hydroxide produced was filtered out and washed. The filtrate was boiled with sodium carbonate to expel ammonia and the fluorine was then determined in the usual way as calcium fluoride.

The active oxygen and water were determined by weighing out a sample in a short hard glass tube closed at one end. A plug of asbestos was placed in the tube above the salt to prevent loss by decrepitation, and the tube was then connected to the top of a Hempel's gas burette by means of a short piece of rubber tubing. On gently heating the tube, water was expelled at first, and then at a higher temperature oxygen was evolved, and from its corrected volume the amount of active oxygen in the salt was easily calculated. The tube was then reweighed and its loss in weight gave the sum of the active oxygen and water, the latter being finally determined by difference. 
The tantalum and potassium were determined as in the case of the other double fluorides.

\begin{tabular}{|c|c|c|c|c|c|}
\hline \multirow[b]{2}{*}{$\ldots \ldots$} & \multicolumn{2}{|c|}{$\begin{array}{c}\text { Calculated for } \\
{ }_{2 \mathrm{KF}} \mathrm{TaO} \mathrm{F}_{3} \cdot \mathrm{H}_{2} \mathrm{O}\end{array}$} & \multicolumn{3}{|c|}{ Piccini. } \\
\hline & $7^{8}$ & 19.21 & 19.56 & & 18.83 \\
\hline $\mathrm{Ta} \ldots \ldots \ldots$ & 183 & 45.07 & 44.87 & 44.28 & 44.82 \\
\hline${ }_{5} \vec{F} \quad \ldots \ldots \ldots$ & 95 & $23 \cdot 40$ & $23 \cdot 76$ & & 23.82 \\
\hline O (active) .... & 16 & 3.94 & 3.96 & & 3.78 \\
\hline $\mathrm{H}_{2} \mathrm{O} \ldots \ldots \ldots$ & 18 & $4 \cdot 44$ & 4.24 & $4 \cdot 34$ & 4.25 \\
\hline \multirow[t]{3}{*}{$\mathrm{O}$} & 16 & 3.94 & $3.6 I$ & & \\
\hline & 406 & 100.00 & 100.00 & & \\
\hline & & IDI & LLT. & & \\
\hline
\end{tabular}

${ }_{2} R b F . T_{a F_{5}}$. - This salt was obtained in very small amounts by Pennington. It was formed when the two fluorides were brought together in dilute aqueous hydrofluoric acid and consisted of small white needles. It was recrystallized from water containing a small amount of acid, but not from pure water, as a white, insoluble salt separated as in the case of the potassium salt. It was much more soluble than the latter, I part of the salt dissolving in about 40 parts of water. The following analytical results were obtained:

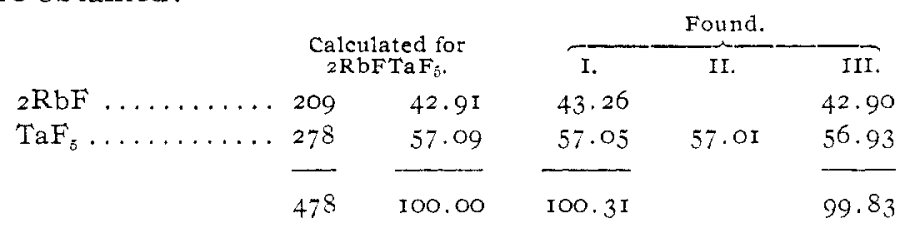

On recrystallizing this salt several times from strong hydrofluoric acid a granular salt was obtained which gave 50 per cent. of $\mathrm{Ta}_{2} \mathrm{O}_{5}$ on analysis. This approaches the formula $3 \mathrm{RbF}_{2} \mathrm{TaF}_{5}$, which requires $5 \mathrm{I} .3$ per cent. of $\mathrm{Ta}_{2} \mathrm{O}_{5}$, but repeated efforts to get a pure salt were without success. The results, however, seemed to point to the existence of a double fluoride richer in tantalum fluoride than the 2 : I salt.

\section{SAITS OF CAESIUM.}

Tantalum fluoride forms two different double fluorides with caesium fluoride. To prepare these salts pure caesium fluoride was obtained after the following manner: Commercial caesium carbonate was converted into caesium nitrate by solution in nitric acid. The solution was evaporated to dryness to expel the excess 
of acid, and the salt was then dissolved in $I:$ I hydrochloric acid and treated with the equivalent amount of iodine. On cooling the salt $\mathrm{CsCl}_{2} \mathrm{I}$, described by $\mathrm{H}$. L. Wells, ${ }^{2}$ crystallized out. This salt was recrystallized from I: I hydrochloric acid, and when tested by means of the spectroscope was found to be free from all other alkali metals. On careful ignition this trihalide gave pure caesium chloride, which was converted into the carbonate by the method of J. I. Smith, ${ }^{2}$ which consists in a conversion of the chloride to nitrate by evaporation with nitric acid, and the evaporation of the caesium nitrate solution with pure oxalic acid and ignition of the dry residue. The hydrofluoric acid solution of this carbonate gave, on concentration, clear colorless prismatic crystals, and was used for the preparation of the following salts:

CsF.TaF ${ }_{5}$. This salt is the most definite and characteristic double fluoride of caesium and tantalum. It may be best prepared by bringing together solutions of the two fluorides in the calculated proportions, and recrystallizing from a rather strong solution of hydrofluoric acid. Brilliant, glistening thombohedral crystals were formed. They were recrystallized unchanged from water containing hydrofluoric acid. This salt was also obtained when the $2:$ I salt was crystallized two or three times from concentrated hydrofluoric acid, or when a mixture of caesium fluoride with a large excess of tantalum fluoride was allowed to crystallize.

The first two analyses are for a salt recrystallized from strong hydrofluoric acid, while the third analysis gives the results obtained for a salt crystallized in the presence of a large excess of tantalum fluoride.

\begin{tabular}{|c|c|c|c|c|c|}
\hline \multirow{4}{*}{$\begin{array}{l}\mathrm{CsF} \\
\mathrm{TaF}_{3}\end{array}$} & \multirow{2}{*}{\multicolumn{2}{|c|}{$\begin{array}{c}\text { Calculated for } \\
\text { CsF,TaFs. } \\
\text { Per cent. }\end{array}$}} & \multicolumn{3}{|c|}{ Found. } \\
\hline & & & $\begin{array}{l}\text { I. } \\
\text { Per cent. }\end{array}$ & Per cent. & $\begin{array}{l}\text { III. } \\
\text { Per cent }\end{array}$ \\
\hline & I 52 & $35 \cdot 35$ & $35 \cdot 37$ & $35 \cdot 3 I$ & 35.19 \\
\hline & 278 & 64.65 & 64.59 & 64.22 & 64.43 \\
\hline & 430 & 100.00 & 99.96 & 99.53 & 99.62 \\
\hline
\end{tabular}

Crystallography.-As stated above, this salt crystallized in the rhombohedral division of the hexagonal system. Many of the crystals showed faces of the right and left rhombohedron together with those of a hexagonal prism of the second order, as in the figure. At times the eight faces of one zone grew to a considerable

1 Amer. Jour. Sci, 43, 17 (1892).

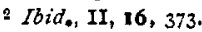


length, giving the crystal a marked prismatic aspect. The faces of the crystals were smooth and brilliant, and gave very sharp

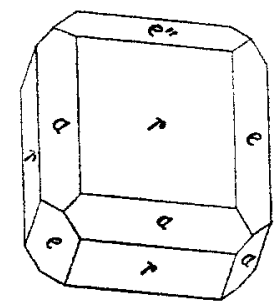

Fig. 5.

reflections. The measurements given represent the mean of a number of very concordant observations.

Rhombohedral.-Axis $\dot{\mathrm{C}}=\mathrm{I} .0467$.

\begin{tabular}{|c|c|c|c|}
\hline & $=$ & Measured, & Calculated \\
\hline$e e^{\prime}$, & OII 2 IOI $2=$ & $53^{\circ}$ I $3^{\prime}$ & $53^{\circ} \times 3^{\prime}$ \\
\hline $\begin{array}{l}\text { ae, } \\
\text { aa', }\end{array}$ & $\begin{array}{l}\text { II } \overline{2} \mathrm{O} \text { OII } 2= \\
\text { II } \overline{2} \mathrm{O} \wedge \overline{\mathrm{I}} 2 \mathrm{I} O=\end{array}$ & $\begin{array}{l}63^{\circ} 23 \frac{1}{2}^{\prime} \\
60^{\circ}\end{array}$ & $\begin{array}{l}63^{\circ} 23 \frac{1}{2} \\
60^{\circ}\end{array}$ \\
\hline
\end{tabular}

${ }_{2}$ CsF.TaF 5 .-This salt was obtained when tantalum fluoride and an excess of caesium fluoride were brought together and allowed to crystallize from a solution containing a slight amount of hydrofluoric acid. It consisted of small needles, and was much more soluble than the corresponding potassium salt. It could not be crystallized from water as it tended to pass into the $\mathrm{I}: \mathrm{I}$ salt.

A nalysis,-Caesium sulphate was found to be distinctly volatile at a red heat, so that care had to be exercised in its ignition. In order to convert all of the acid sulphate into the normal sulphate the mass was ignited with ammonium carbonate, this being repeated until the crucible had reached a constant weight. This same precaution was used in the ignition of rubidium sulphate, which was also somewhat volatile at elevated temperatures.

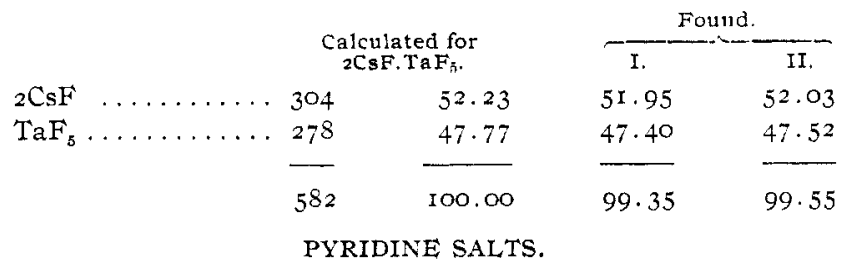

${ }_{3}\left(\mathrm{C}_{5} \mathrm{H}_{5} \mathrm{~N} . \mathrm{HF}\right) .2 \mathrm{TaF}_{5} .2 \mathrm{H}_{2} \mathrm{O}$.- This salt was formed when a mixture of pyridine hydrofluoride and tantalum fluoride, in a slightly 
acid solution, was concentrated on the water-bath and allowed to cool. The salt, much more soluble in hot than in cold water, was easily recrystallized from water containing a trace of hydrofluoric acid. When dry, it smelled quite strongly of pyridine. On standing in contact with the air the crystals soon lost their luster, becoming white and opaque. The freshly prepared crystals were soluble in water, methyl and ethyl alcohols, pyridine and hot nitrobenzene, but not in benzene.

Analysis.-The tantalum was obtained by igniting a sample of the salt with sulphuric acid. The carbon and hydrogen were determined by combustion, the sample being mixed with a large amount of lead chromate. The nitrogen was determined by the method of Dumas. The fluorine was determined in two ways: first, as calcium fluoride after the removal of the tantalum with ammonium hydroxide; second, by titration, using litmus as an indicator. At first an excess of the alkali was run into the solution of the salt contained in a platinum dish and boiled until all of the pyridine had been expelled. The solution was then made acid and titrated back with the standard alkali. The end-point was not as sharp as could be desired, but the results obtained were fairly satisfactory.

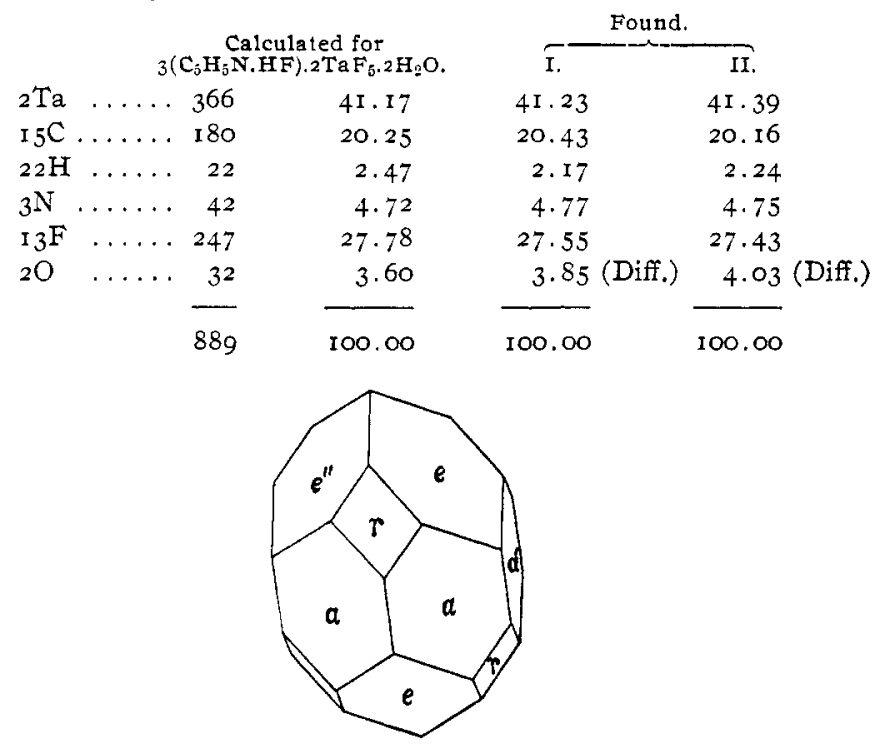

Fig. 6. 
Crystallography.-This salt crystallized in the hexagonal system and had very much the same habit as the $\mathrm{r}$ : I caesium salt. The crystals were easily obtained by allowing the solution to evaporate spontaneously. They grew at times to a diameter of $10 \mathrm{~mm}$. or more. Their faces gave fair images of the signal when measured with the goniometer. The crystal habit is shown in Fig. 6.

Rhombohedral. -Axis c $=1.6259$.

\begin{tabular}{|c|c|c|c|}
\hline & & Measured. & Calculated. \\
\hline $\mathrm{rr}^{\prime}$ & IOẼI $\bar{I} I O I=$ & $99^{\circ} 42^{\prime}$ & \\
\hline $\mathrm{ra}$ & IOII $\triangle \bar{I} 2 \bar{I} O=$ & $90^{\circ}$ & $90^{\circ}$ \\
\hline$a a^{\prime}$ & II $\overline{2} \mathrm{O} / \overline{\mathrm{I}} \overline{\mathrm{I}} \overline{\mathrm{I}}=$ & $60^{\circ}$ & $60^{\circ}$ \\
\hline $\mathrm{ee}^{\prime}$ & 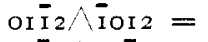 & $72^{\circ} 4 \mathrm{I}^{\prime}$ & $72^{\circ} 42^{\prime}$ \\
\hline ae, & II $\overline{2} 0 \wedge 01 \bar{I}_{2}=$ & $53^{\circ} 39^{\frac{1}{2}}$ & $53^{\circ} 39^{\prime}$ \\
\hline $\mathrm{re}^{\prime}$ & IOİI $\overline{\text { IOI } 2}=$ & $105^{\circ} \quad 6 \frac{1}{2}^{\prime}$ & $105^{\circ} 9^{\prime}$ \\
\hline
\end{tabular}

$C_{5} H_{5} N . H F . T a F_{5}$. - It was found that when the preceding salt was recrystallized from strong hydrofluoric acid a new salt separated in the form of long slender needles. These needles were recrystallized from strong hydrofluoric acid and gave the following results on analysis :

\begin{tabular}{ccr}
\multicolumn{4}{c}{ Calculated for } \\
$\mathrm{C}_{5} \mathrm{H}_{5} \mathrm{~N} . \mathrm{HF} . \mathrm{TaF}$. & Found. \\
$\mathrm{Ta}_{2} \mathrm{O}_{5} \ldots \ldots \ldots \ldots \ldots \ldots \ldots \ldots$ & 59.16 & 58.98 \\
$\mathrm{~F} \quad \ldots \ldots \ldots \ldots \ldots \ldots \ldots$ & 30.24 & 30.02 \\
$\mathrm{~N} \quad \ldots \ldots \ldots \ldots \ldots \ldots \ldots$ & $3.7 \mathrm{I}$ & 4.03
\end{tabular}

Crystalline salts were also obtained with methylamine, ethylamine, triethylamine and quinoline, but their analyses were not completed. There is little doubt but that a large number of such compounds can be obtained, and the subject will receive further attention.

\section{AMMONIUM SALTS.}

The investigation of the ammonium salts was not completed, but enough was accomplished to prove that other ratios than the $2:$ I salt exist. For example, on concentrating a solution containing tantalum fluoride and an excess of ammonium fluoride a salt was obtained, 0.6035 gram of which gave $0.345^{\circ}$ gram of $\mathrm{Ta}_{2} \mathrm{O}_{5}$, or 57.17 per cent. That required for $3 \mathrm{NH}_{4} \mathrm{~F} . \mathrm{TaF}_{5}$ is 57.33 per cent. These salts will receive further attention. The $2: \mathrm{I}$ salt was studied by Marignac and it was used by him in a determination of the atomic weight of tantalum. He obtained the following results, and from them the atomic weight of tantalum has been calculated, using $\mathrm{H}=\mathrm{I} .008, \mathrm{~N}=\mathrm{I} 4.04$ and $\mathrm{F}=\mathrm{I} 9$. 


$\begin{array}{cccc}2 \mathrm{NH}_{4} \mathrm{~F} . \mathrm{TaF}_{5} . & \mathrm{Ta}_{2} \mathrm{O}_{5} . & \text { Per cent. } \mathrm{Ta}_{2} \mathrm{O}_{5} . & \text { At. } w t . \text { of Ta. } \\ 0.986 & 0.622 & 63.08 & 180.64 \\ 2.133 & 1.349 & 63.24 & 182.16 \\ 2.012 & 1.273 & 63.27 & 182.45 \\ 2.007 & 1.273 & 63.42 & 183.89\end{array}$

The great solubility of this salt precludes its use in accurate atomic weight determinations, as one could scarcely hope to obtain a perfectly pure and definite compound. In fact, the tendency of all these double fluorides to form more than one ratio presents an objection to their use as material for atomic weight determinations. Of the salts mentioned in this paper, the $2: \mathrm{I}$ potassium and the 3 : I sodium are by far the most desirable for such a purpose, as they may be obtained in a high state of purity by repeated crystallizations. However, other compounds of tantalum should be sought with which to accurately determine this constant.

\section{PERTANTALATES.}

While testing tantalum hydroxide it was noticed that it dissolved readily in an alkaline solution of hydrogen peroxide. In one instance tantalum hydroxide, which had been prepared by precipitating a solution of ammonium tantalum fluoride with ammonium hydroxide and washing the precipitate with water, was dissolved in a dilute solution of hydrogen peroxide containing some potassium hydroxide, and, on standing over night, a crystalline salt separated, which proved to be potassium pertantalate. This seemed to be a very convenient method for the preparation of the alkaline pertantalates, and it was therefore carried out on a larger scale.

A number of the salts of pertantalic acid have been described by P. Melikoff and L. Pissarjewsky. ${ }^{1}$ Among others, they obtained the following:

$$
\begin{aligned}
& \mathrm{K}_{3} \mathrm{TaO}_{8}+\frac{1}{2} \mathrm{H}_{2} \mathrm{O} \\
& \mathrm{Na}_{3} \mathrm{TaO}_{8}+\mathrm{H}_{2} \mathrm{O} \\
& \mathrm{CaKTaO}_{8}+4 \frac{1}{2} \mathrm{H}_{2} \mathrm{O}
\end{aligned}
$$

The sodium and potassium salts were obtained as white precipitates upon the addition of alcohol to a dilute hydrogen peroxide solution of the corresponding tantalate. The third salt mentioned above was obtained from the potassium salt by double decomposition with calcium chloride.

1 Z. anorg. Chem., 20, 340 (189g). 


\section{Potassium Pertantalate, $K_{3} T a O_{8}$.}

Twenty grams of stick potassium hydroxide were dissolved in about $250 \mathrm{cc}$. of a 3 per cent. solution of hydrogen peroxide, and to this solution tantalum hydroxide, prepared as indicated above, was added as long as solution took place. The solution was then filtered and allowed to stand in a cool place over night. The anhydrous potassium pertantalate separated in small hard crystals nearly white in color. This salt was stable at the ordinary temperature. It dissolved slowly in water, and oxygen was evolved when its aqueous solution was boiled. The dry salt decomposed violently when treated with concentrated sulphuric acid.

Analysis.-A sample of the salt was dissolved in water, a few drops of sulphuric acid added and the solution boiled. The tantalum separated as the hydroxide, which was filtered off and weighed. The filtrate was evaporated and the potassium determined as sulphate.

The active oxygen in this salt was determined as outlined under the potassium salts.

The analyses given are for two separate preparations.

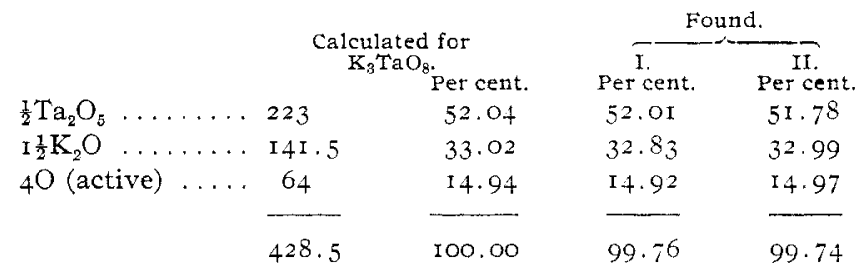

Sodium Pertantalate, $\mathrm{Na}_{3} \mathrm{TaO}_{8}+\mathrm{I}_{4} \mathrm{H}_{2} \mathrm{O}$.

This salt was prepared in the same manner as the potassium salt. It crystallized from the solution in large, but not well-defined, crystals, which had a faint yellow color. On exposure to the air these crystals rapidly lost the greater part of their water of crystallization, falling to a white powder. For analysis the crystals were dried between folds of filter-paper and weighed out as rapidly as possible.

\begin{tabular}{|c|c|c|c|}
\hline \multirow{5}{*}{ 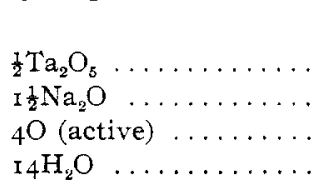 } & \multicolumn{2}{|c|}{$\begin{array}{c}\text { Calculated for } \\
\mathrm{Na}_{3} \mathrm{TaO}_{8}+\mathrm{I}_{4} \mathrm{H}_{2} \mathrm{O}\end{array}$} & \multirow{2}{*}{$\begin{array}{l}\text { Found. } \\
35.34\end{array}$} \\
\hline & 223 & 35.28 & \\
\hline & 93 & 14.72 & 15.14 \\
\hline & 64 & IO. 13 & 10.09 \\
\hline & 252 & 39.87 & 38.89 \\
\hline & 632 & 100.00 & $99 \cdot 4^{6}$ \\
\hline
\end{tabular}


On adding the chlorides of calcium, strontium or barium to solutions of the above-described pertantalates, flocculent precipitates were produced. These compounds will receive further attention.

University of Pennsyluania.

\section{A CONTRIBUTION TO THE CHEMISTRY OF THE TELLURATES. ${ }^{1}$}

By Edgar BURton HUtchiss, JR.

Received July 10, 1905.

THIs work was undertaken with a view of preparing a number of the tellurates and studying their properties. The work has been confined for the most part to the salts of potassium, silver, and mercury. Careful attention has been devoted to their preparation in the crystalline form. The ease with which the tellurates of silver and mercury are decomposed by water has made this problem particularly difficult. For the most part the salts appear at first as amorphous precipitates of varying composition and quickly alter in the mother-liquor, their subsequent composition depending on the conditions in the solution.

The telluric acid used in this work was obtained by purifying and oxidizing electrolytic tellurium prepared by the Baltimore Copper Co. This tellurium contains silver, copper, and selenium as its principal impurities. The acid was prepared by the method described by Staudenmaier. ${ }^{2}$ By this method free telluric acid is ottained by oxidation of tellurous acid by means of chromic acid. In many respects this method is superior to those in which sulphuric acid is used to set the telluric acid free. The vield is greater, the operation is more direct, and the sulphuric and selenic acids are eliminated in one of the first steps of the process which consists in purifying tellurium dioxide. These acids are apt to contaminate telluric acid prepared by the other methods, unless special precautions are taken.

The method as carried out in this work is as follows:

Tellurium is dissolved in aqua regia and the resulting solution freed from nitric acid by evaporating with excess of hydrochloric acid. After the hydrochloric acid solution has been diluted and

1 From a thesis submitted for the degree of Doctor of Philosophy, University of Wisconsin, 1905 .

2 Z. anorg. Chem., 10, 189. 